\title{
Removal of Carbaryl Pesticide from Aqueous Solution by Adsorption on Local Clay in Agadir
}

\author{
Mahmoud El Ouardi*, Said Alahiane, Samir Qourzal, Abdelhadi Abaamrane, \\ Ali Assabbane, Jamâa Douch \\ Physical Chemistry Laboratory, Photocatalysis and Environment Team, Department of Chemistry, Faculty of Science, \\ Ibn Zohr University, Agadir, Morocco \\ Email: *elouardi.mahmoud@gmail.com
}

Received May 13, 2013; revised June 12, 2013; accepted June 29, 2013

Copyright (C) 2013 Mahmoud El Ouardi et al. This is an open access article distributed under the Creative Commons Attribution License, which permits unrestricted use, distribution, and reproduction in any medium, provided the original work is properly cited.

\begin{abstract}
This study was conducted to assess the removal efficiency of pesticide (Carbaryl) used in Souss Massa region (Agadir city), on a clay originated from barrage situated in Agadir. The adsorption of Carbaryl from aqueous solution by local clay as a low-cost, natural and eco-friendly adsorbent was investigated. Different physicochemical parameters were analyzed: adsorbent mass, ionic strength $\left(\mathrm{NaNO}_{3}\right)$, initial concentration of pollutant, temperature, and $\mathrm{pH}$. The empirical results showed that all these parameters have an impact on the retention of pesticide on the clay. The equilibrium uptake was increased with an increase in the initial pesticide concentration in solution. The results of adsorption were fitted to the Langmuir and Freundlich isotherms. The Freundlich model represented the adsorption process better than Langmuir model, with correlation coefficients $\left(\mathrm{R}^{2}\right)$ values ranged from 0.97 to 0.99 . This study has shown that the natural clay is a solid that has got an important adsorption capacity, which may be used in treatment and depollution of water.
\end{abstract}

Keywords: Carbaryl; Clay; Adsorption Isotherms; Water Treatment

\section{Introduction}

Using pesticides has become a common practice in the agricultural sector. Though those products improve the percentage of yields, their use enhances more and more questions about their impact upon human health as well as environment. The potential risks of human health are noticeably seen through the detection of pesticides residues in water, foodstuffs and even in breast milk [1,2].

The objective of applying pesticides is to protect plant against damage. However, crops can't absorb only a part of the pesticides quantity. The rest is exposed to evaporation volatilization and infiltration in order to create a contamination to groundwater.

Therefore, we are interested in to eliminate Carbaryl (1-Naphthalene-N-methylcarbamate) by the adsorption process under static conditions that is an insecticide nonionic, widely used in agriculture [3].

The adsorption remains a broadly used technique and easy to implement. The activated carbon is the most used adsorbent due to its extreme capacity of adsorption of organic materials [4]. However, this adsorbent has a high

${ }^{*}$ Corresponding author. cost and remains difficult to regenerate for multiple uses. The search of another efficient and less expensive adsorbent is an interesting task. In this context, the utilization of the clay as an adsorbent has a great interest due to its efficiency and availability [5].

In this work, the adsorption capacity for Carbaryl reactive was determined using local clay, which is a natural and available adsorbent in Agadir. This adsorbent was used in its unprocessed state (size of particles $<80 \mu \mathrm{m}$ ). The parameters that influence adsorption such as pesticide initial concentration, contact time, adsorbent mass, solution $\mathrm{pH}$, ionic strength and temperature were investigated. The description of the adsorption of the isotherm was done by applying linear transformations of two isotherms: Langmuir and Freundlich models.

\section{Materials and Methods}

The untreated clay used in this work is crushed then sifted in order to get fractions $<80 \mu \mathrm{m}$. Afterwards, the support is rinsed many times with demineralized water, of $\mathrm{pH}=6.7$ and of conductivity $=0.7 \mu \mathrm{S}$. After every rinse, the clay is put in a sedimentation test, and during 
one hour of decantation, we recover the two thirds of supernatant volume. Finally, it is placed in an oven between $100^{\circ} \mathrm{C}$ and $110^{\circ} \mathrm{C}$ during $24 \mathrm{~h}$, before being subjected to different adsorptions.

The clay is characterized by diffraction of $\mathrm{X}$ rays (XRD), using the diffract meter XPERT-PRO type PW3064, with copper anticathode. The spectrum of XRD shows that the untreated clay is a mixture of Kaolinite, Quartz, Muscovite, calcite and dolomite (Figure 1).

The surface area of clay was determined by nitrogen $\left(\mathrm{N}_{2}\right)$ adsorption-desorption isotherms at $(77 \mathrm{~K})$ using an automated gas sorption system (Micromeritics, QUANTACHROME instrument). The specific surface area was calculated by the Brunauer-Emmett-Teller (BET) method, it is equal to $32.52 \mathrm{~m}^{2} / \mathrm{g}$.

The morphology of the clay powder particles was observed by scanning electron microscopy (SEM, using ZEISS ULTRA PLUS) with a coupled energy dispersive spectroscopy (EDS), at $5 \mathrm{kV}$, after gold coating. The morphological aspects of the powder particles of clay are outlined in the Figure 2. The porosity of the surface is clearly visible. The scanning electron micrograph of this figure shows the typical regular shapes of the clay particles. The powder is rich in porous particles with fibrous morphology and also of angular-shaped particles of quartz and/or Kaolinite.

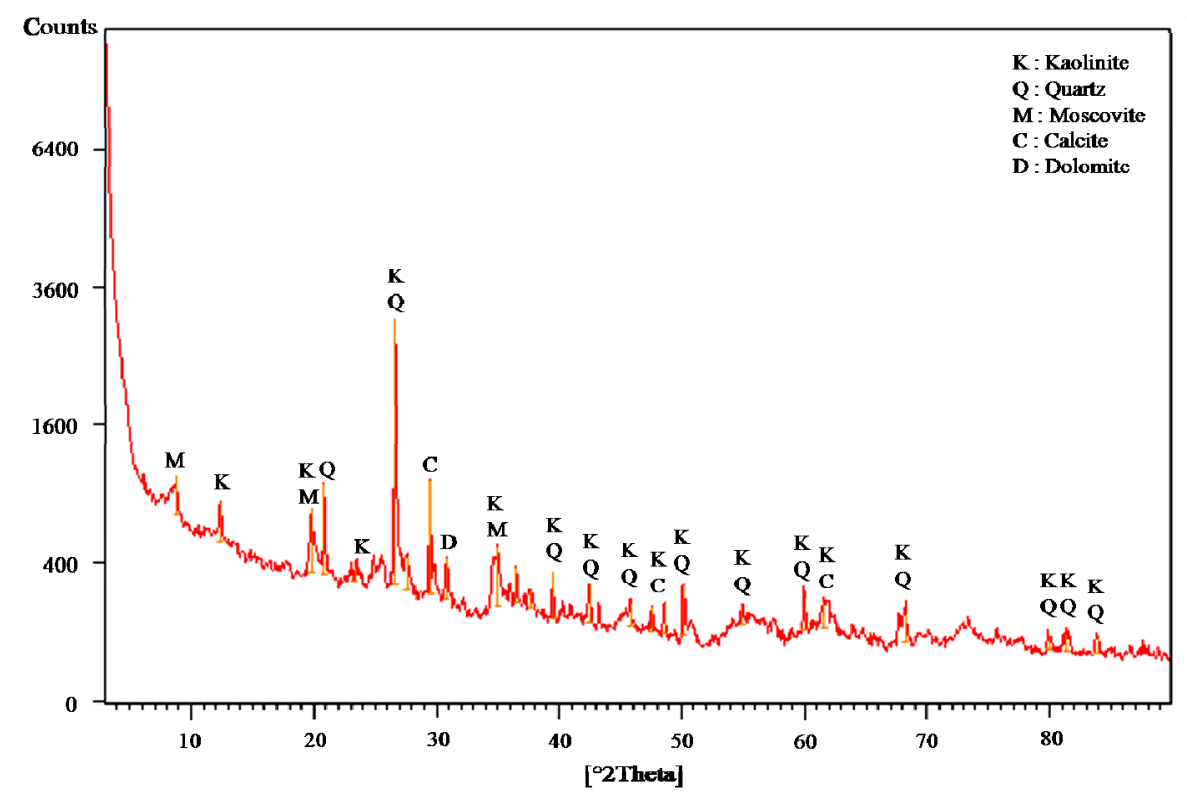

Figure 1. X rays difraction of the local clay.

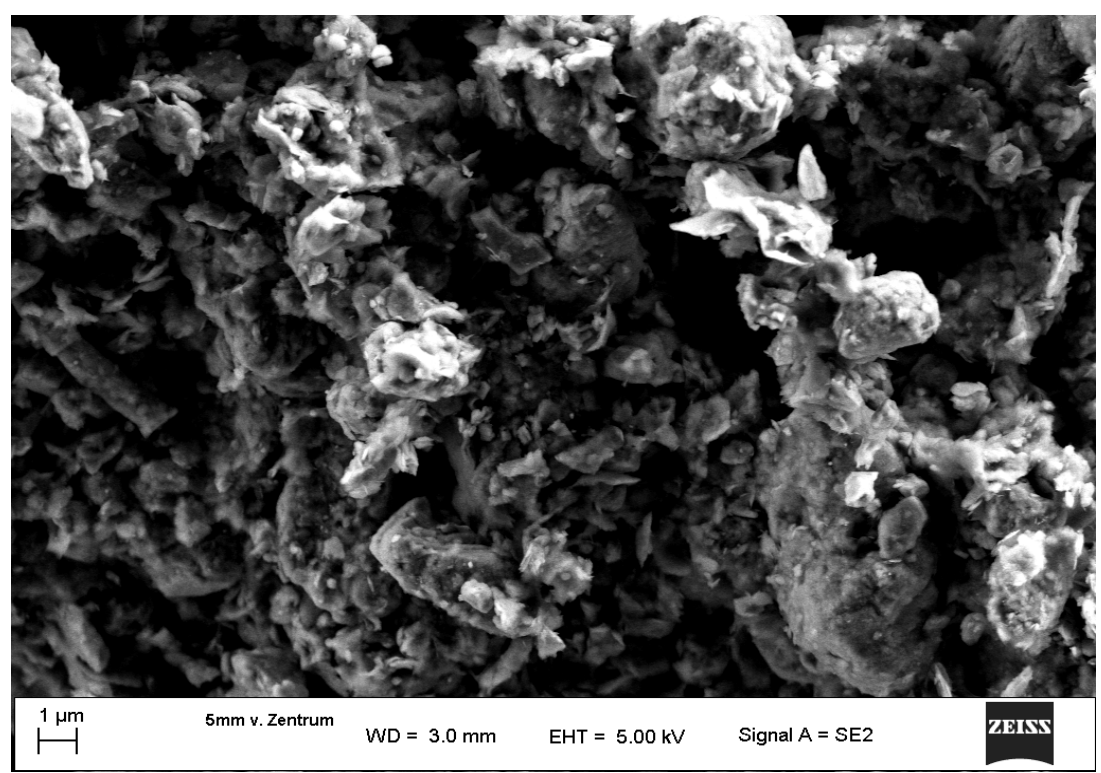

Figure 2. SEM micrograph of the local clay particles. 
The clay is also characteerized by the utilization of dispersive energy of spectroscopy (EDS, type X'Pert Pro, PANALYTICAL) (Figure 3). The elements that constitute the clay are given in atomic and mass percentage in Table 1.

The Carbaryl used in this study was purchased from Sigma-Aldrich and used without further purification. The chemical structure of the pesticide $\left(\lambda_{\max }=280 \mathrm{~nm}\right)$ is depicted in Figure 4. All carbaryl solutions used in this study were prepared by weighing and dissolving the required amounts carbaryl in distilled water.

Adsorption tests were performed in a set of erlenmeyer flasks where $250 \mathrm{ml}$ of Carbaryl solutions with initial concentrations of $4-18 \mathrm{mg} / \mathrm{l}$ were placed in these flasks. Equal mass of $1 \mathrm{~g} / \mathrm{l}$ of the clay was added to each flask and kept in an isothermal shaker of $350 \mathrm{rpm}$ at $20^{\circ} \mathrm{C}$ for $120 \mathrm{~min}$ to reach equilibrium. The $\mathrm{pH}$ of the solutions was original without any $\mathrm{pH}$ adjustment (6.3).

Similar procedures were followed for another two sets of erlenmeyer flask containing the same initial Carbaryl concentrations and same adsorbent dosage, but were kept under $20^{\circ} \mathrm{C}$ and $60^{\circ} \mathrm{C}$ for temperature studies. Aqueous samples were taken from each of the Carbaryl solutions at preset time intervals using disposable syringes and the

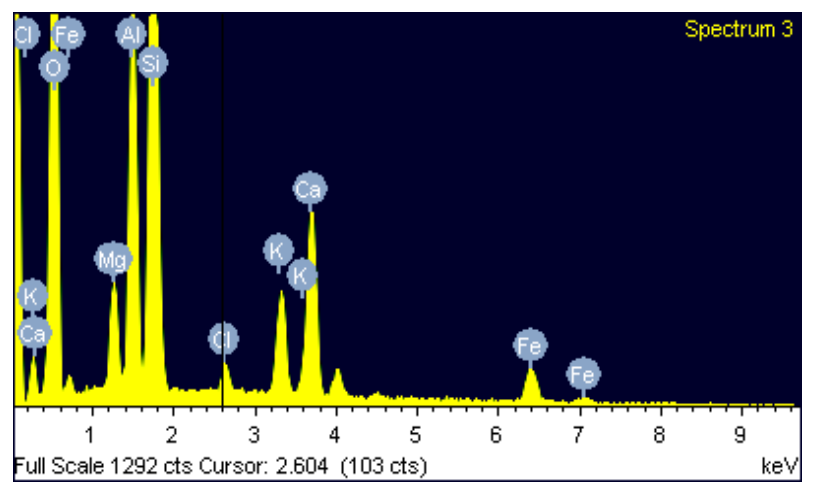

Figure 3. Dispersive energy spectrum of clay spectroscopie (EDS).

Table 1. Atomic and mass percentage of the clay constituents.

\begin{tabular}{ccccccccc}
\hline Elements & $\mathrm{O}$ & $\mathrm{Mg}$ & $\mathrm{Al}$ & $\mathrm{Si}$ & $\mathrm{Cl}$ & $\mathrm{Ca}$ & $\mathrm{K}$ & $\mathrm{Fe}$ \\
\hline \% Atomic & 65.73 & 2.06 & 6.45 & 15.28 & 0.60 & 5.11 & 2.45 & 2.33 \\
\% Mass & 48.76 & 2.32 & 8.06 & 19.90 & 0.99 & 9.49 & 4.44 & 6.04 \\
\hline
\end{tabular}<smiles>CNC(=O)Oc1cccc2ccccc12</smiles>

Figure 4. Carbaryl chemical structure. concentrations were then analyzed. All samples were filtered (through a $0.45 \mu \mathrm{m}$ Millipore) prior to analysis in order to minimize interference of the particles fines with the analysis. Afterwards, the filtrate was immediately dosed by spectrophotometer type UV-visible 2300TECHCOMP at $280 \mathrm{~nm}$.

The amount of adsorption at equilibrium, Qads (mg/g), was:

$$
\mathrm{Q}_{\mathrm{ads}}=\frac{\left(\mathrm{C}_{0}-\mathrm{C}_{\mathrm{e}}\right)}{\mathrm{R}}
$$

with:

$\mathrm{Q}_{\text {ads }}$ : Quantity of pesticide adsorbed per gram of adsorbent $(\mathrm{mg} / \mathrm{g})$.

$\mathrm{C}_{0}$ : Initial concentration $(\mathrm{mg} / 1)$.

$\mathrm{C}_{\mathrm{e}}$ : Equilibrium concentration ( $\left.\mathrm{mg} / \mathrm{l}\right)$.

$\mathrm{R}$ : Mass of adsorbent per litre of aqueous solution $(\mathrm{g} / 1)$.

\section{Results and Discussion}

\subsection{Adsorption Kinetics}

The kinetic study of adsorption is an important step to evaluate the contact time necessary for reaching the equilibrium. The kinetics is achieved at initial $\mathrm{pH}$ of the solution for an initial concentration of $10 \mathrm{mg} / 1$, with a mass of clay of $1 \mathrm{~g} / 1$ and at $\mathrm{T}=20^{\circ} \mathrm{C}$. The variation of the quantity adsorbed by the pollutant as function of time is illustrated in Figure 5.

It is clear from Figure 5 that the amount of Carbaryl adsorbed, $\mathrm{Q}_{\mathrm{ads}}$ increased with time. The equilibrium adsorption was achieved in $120 \mathrm{~min}$ for Carbaryl solution. According to this result, we can conclude that adsorption kinetic presents two distinctive steps. The first step corresponds to the transfer of external mass while the second is related to diffusion phenomena (transfer of internal mass).

The adsorption can be controlled by the step of the transfer of adsorbate through the external liquid film and/or that of diffusion of the solute inside the adsorbent particles $[6,7]$.

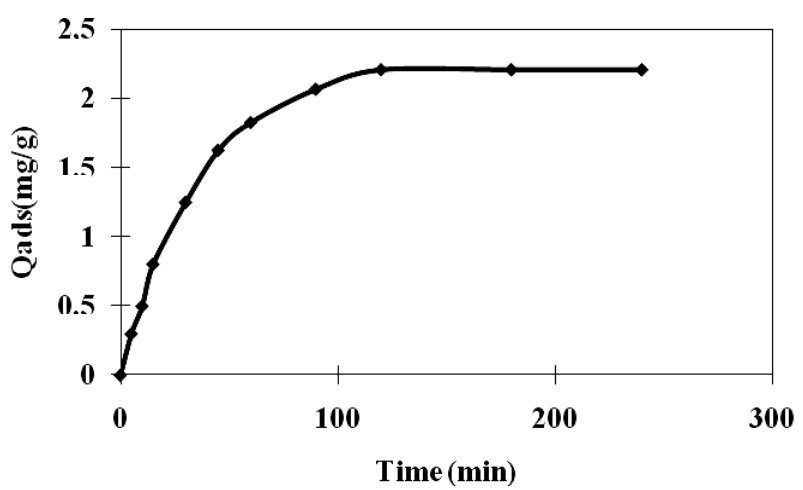

Figure 5. Adsorption kinetic of Carbaryl $\left(C_{0}=10 \mathrm{mg} / \mathrm{l}\right)$ on the clay. 


\subsection{Effect of Adsorbent Quantity}

In order to estimate the optimal quantity of the clay to be added, the tests were done on some solutions of Carbaryl of a concentration of $10 \mathrm{mg} / 1$ at initial $\mathrm{pH}$, while varying the $\mathrm{R}$ ratio of $1 \mathrm{~g} / \mathrm{l}$ until $6 \mathrm{~g} / 1$. The results obtained in the equilibrium are represented in Figure 6.

It appears through these results, that an increase in the clay mass of $1 \mathrm{~g} / \mathrm{l}$ until $6 \mathrm{~g} / \mathrm{l}$ results in a decrease of the residual concentration of pesticide. According to the curves in Figure 6, we found that for high amounts of clay, the adsorption kinetics is quicker, and the equilibrium time decreases as well as the clay mass increases to reach $60 \mathrm{~min}$ for $6 \mathrm{~g} / 1$. The transfer rate of the matter is proportional to the concentration gradient as well as the exchange surface [7]. In the other case, the initial concentration in pesticide is constant and the adsorption rate depends only of the exchange surface.

To give further explanation concerning the efficiency of our solid adsorption of this pesticide, we have postponed in Figure 7 the evolution of pollutant elimination percentage of aqueous phase according to the adsorbent masses. We found that the elimination percentage increases as the adsorption mass increases $(75 \%$ for $R=6$ $\mathrm{g} / 1$ ). This improvement of the elimination percentage can be justified by the fact that if the mass of the solid in the solution is important, and likewise the number of adsorption sites. Consequently, the probability of encountering (molecule-site) increases as well, leading to a better retention [8].

\subsection{Effect of Ionic Strength on Pesticide Adsorption}

Generally, the effect of the ionic strength depends on the adsorbate nature, the adsorbent and those agents employed to control the ionic strength $\left(\mathrm{NaCl}, \mathrm{NaNO}_{3}\right.$, $\mathrm{NaClO}_{4}, \mathrm{CaCl}_{2}$ ), and possibly their concentration $[9,10]$. Moreover, the rise in the ionic strength may cause an increase or a decrease in the adsorption. The latter may

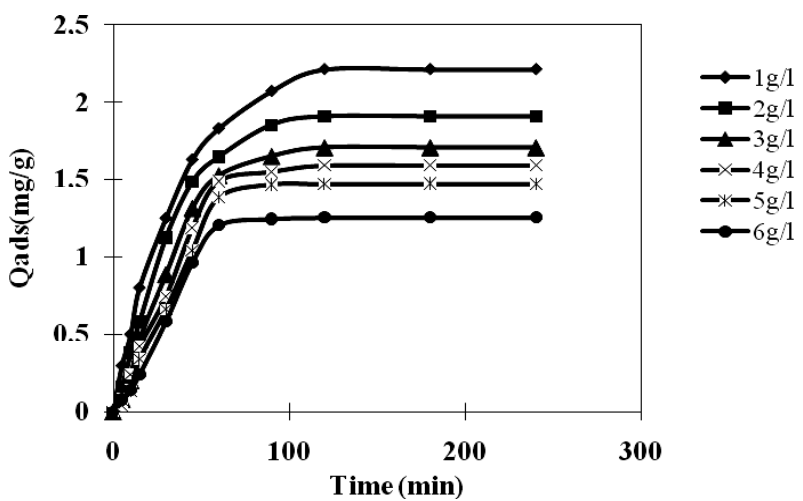

Figure 6. The clay mass effects on the kinetics adsorption of Carbaryl $\left(\mathrm{C}_{0}=10 \mathrm{mg} / \mathrm{l}\right)$. also be insensitive to ionic strength variations [11].

In order to study ionic strength effect we added to our mixture some variable concentrations of sodium nitrate $\left(\mathrm{NaNO}_{3}\right)$ going from $5 \times 10^{-4} \mathrm{M}$ to $10^{-2} \mathrm{M}$. The initial concentration in Carbaryl is $10 \mathrm{mg} / 1$ with a ratio of $1 \mathrm{~g} / 1$ of adsorbent at initial $\mathrm{pH}$. The results are shown in Figure 8.

These curves reports that the adsorption of Carbaryl is inhibited. When the ionic strength increased from 0.0005 to $0.01 \mathrm{M}$, the adsorption onto the clay decreased. It's mainly due to a competitiveness of the adsorption of some nitrate ions with this pesticide. We also remark that the addition of $\mathrm{NaNO}_{3}$ does not change the time of equilibrium of adsorption.

This phenomenon also reported by Anirudhan and Ramachandran 2007 [12]. The effect of salt concentration on pesticide sorption was complex, as had been explained by diffuse double-layer theory: ions that form outer-sphere surface complexes show decreasing adsorption with increasing ionic strength.

\subsection{Pesticide Initial Concentration Effects}

It is clear from Figure 9 that the amount of Carbaryl adsorbed, $Q_{\text {ads }}$ increased with time. The equilibrium adsorption was achieved in 120 min for Carbaryl solution with initial concentrations of $4-18 \mathrm{mg} / 1(\mathrm{R}=1 \mathrm{~g} / 1)$.

The fact that the diffusion of the pesticide molecules

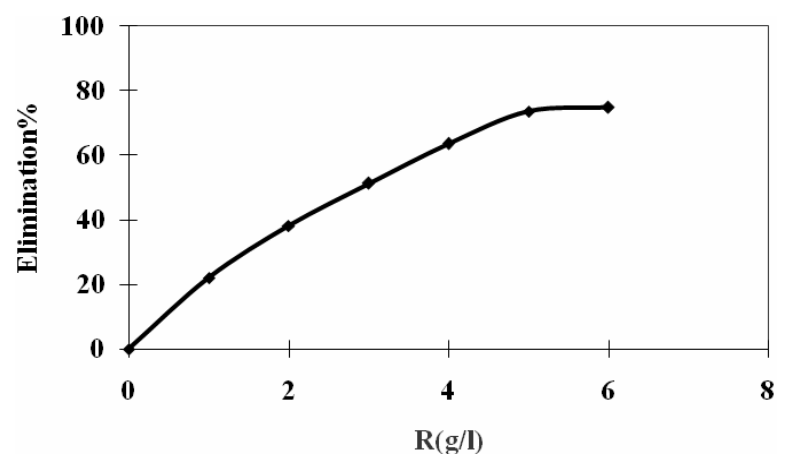

Figure 7. Evolution of pesticide elimination percentage in function of $R$.

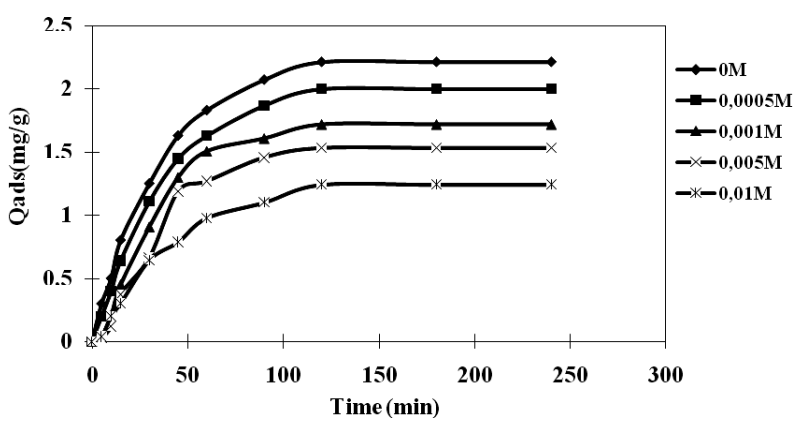

Figure 8. The effect of the addition of $\mathrm{NaNO}_{3}$ on the adsorption of Carbaryl $\left(C_{0}=10 \mathrm{mg} / \mathrm{l}\right)$. 


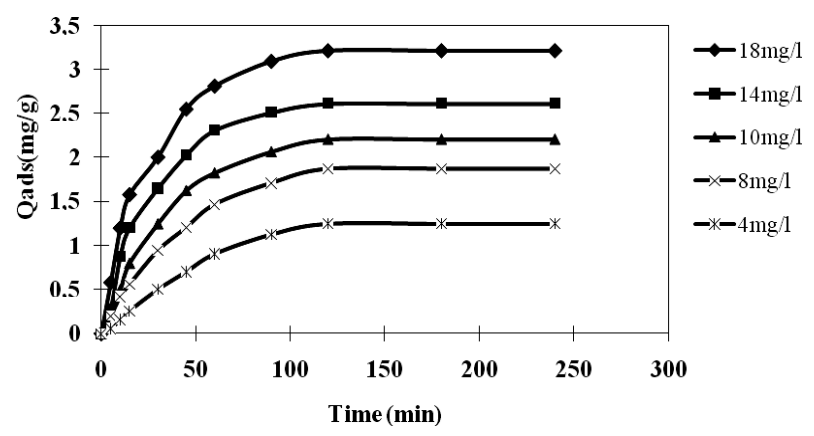

Figure 9. The effect of the initial concentration of Carbaryl $\left(C_{0}=10 \mathrm{mg} / \mathrm{l}\right)$.

of the solution at the surface of the adsorbent is accelerated by the increase of the concentration in pesticides. This observation could be explained by the theory that in the process of Carbaryl adsorption, initially the pesticide molecules have to first encounter the boundary layer effect and then diffuse from the boundary layer film onto adsorbent surface and then finally, they have to diffuse into the porous structure of the adsorbent [13-15]. Therefore, Carbaryl solutions of higher initial concentrations will take relatively longer contact time to attain equilibrium due to higher amount of Carbaryl molecules. The amount of Carbaryl adsorbed at the equilibrium time reflects the maximum adsorption capacity of the adsorbent under those operating conditions. In this study, the adsorption capacity at equilibrium $\left(\mathrm{Q}_{\mathrm{ads}}\right)$ increased from 1.20 to $3.25 \mathrm{mg} / \mathrm{g}$ with an increase in the initial pesticide concentrations from 4 to $18 \mathrm{mg} / \mathrm{l}$. When the initial concentration increased, the mass transfer driving force would become larger, hence resulting in higher adsorption of Carbaryl.

\subsection{Effect of Temperature on Pesticide Adsorption}

Temperature is another important factor affecting adsorption. Figure 10 shows that increase in temperature caused a decrease in adsorption capacity of clay. Adsorbed amounts of Carbaryl on our adsorbent were found as $2.211,2.001,1.897,1.343,1.117 \mathrm{mg} / \mathrm{g}$ at $20^{\circ} \mathrm{C}, 30^{\circ} \mathrm{C}$, $40^{\circ} \mathrm{C}, 50^{\circ} \mathrm{C}$ and $60^{\circ} \mathrm{C}$ respectively. The experiences have been performed at initial $\mathrm{pH}$ by adding $1 \mathrm{~g} / 1$ of solid to some concentration solutions equal to $10 \mathrm{mg} / \mathrm{l}$ in pesticide.

As temperature increases from $20^{\circ} \mathrm{C}$ to $60^{\circ} \mathrm{C}$, the adsorbed amount of chemicals at the same equilibrium concentration decreased, suggesting that adsorption is a process of release of activation energy. Generally, when the temperature increases, the pesticide becomes more soluble. As a consequence, it is less retained by the adsorbent [16-18]. The decrease of the adsorption efficiency in some high temperatures was explained as a number of clay adsorbent particles have been destroyed at a temperature above $40^{\circ} \mathrm{C}$ and the suspension (clay + solution) become homogeneous at a higher temperatures.

\subsection{Effect of Solution pH on Carbaryl Adsorption}

Since hydrogen ions affect the surface charge of the adsorbents and the adsorbate species [19-21], the sorption is greatly affected by the variation of solution $\mathrm{pH}$.

In order to investigate the effect of $\mathrm{pH}$ on adsorption of Carbaryl onto clay, experiments were performed with $10 \mathrm{mg} / 1$ initial concentration between $\mathrm{pH} 3$ and 9 at $20^{\circ} \mathrm{C}$ and $\mathrm{R}=1 \mathrm{~g} / 1$ of clay. As it seen from Figure 11 adsorption decreased with increasing $\mathrm{pH}$. It was observed that the adsorption is highly dependent on $\mathrm{pH}$ since it has strong influence on the surface charge of the adsorbent. Attraction forces between more positively charged surface and Carbaryl are responsible for increasing adsorption with decreasing $\mathrm{pH}$. According to surface chemistry theory, clay particles and pesticide molecules are both surrounded by an electric double layer due to electrostatic interactions.

The isoelectric point (PZC) of the natural adsorbent

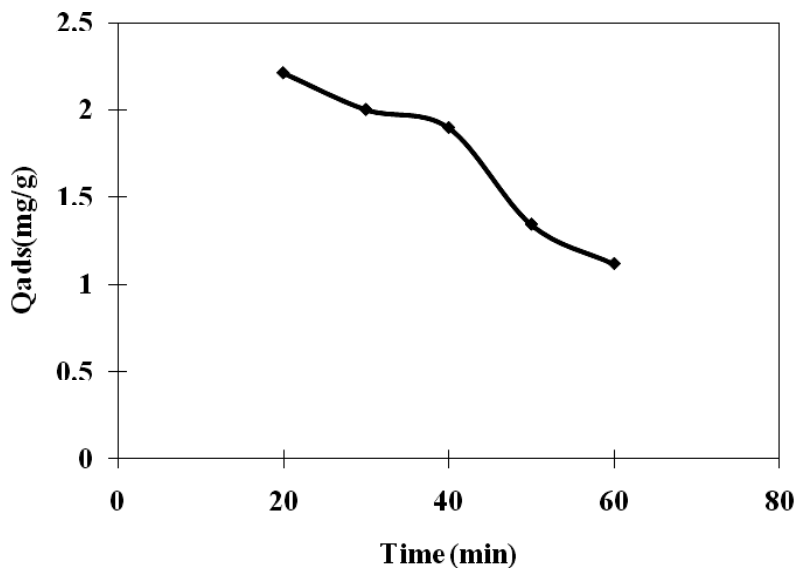

Figure 10. The temperature effects on the Carbaryl adsorbent $\left(C_{0}=10 \mathrm{mg} / \mathrm{l}\right)$.

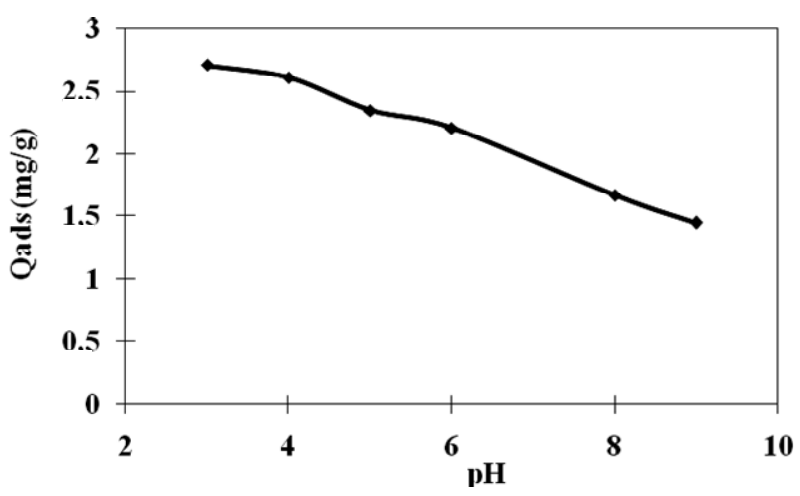

Figure 11. pH effect on Carbaryl adsorption $\left(C_{0}=10 \mathrm{mg} / \mathrm{l}\right)$. 
was found to be at $\mathrm{pH}$ of 5.1. For values of $\mathrm{pH}<\mathrm{PZC}$, the clay surface has been positively charged. In one hand, it favors the adsorption of Carbaryl that is characterized with a high electronic density caused by Kekule forms of two nucleuses. In the other hand, by electrons functional groups which performs Mesomeric effect $(+\mathrm{M})$ due to nitrogen and oxygen atom hybridized $\mathrm{sp}^{3}$, and Inductive effect $(+\mathrm{I})$ caused by methyl group. Additionally, pesticides that have nuclei have a base character [2]. All this has proven affinity between positive surface of the clay and Carbaryl molecule. At $\mathrm{pH}>\mathrm{PZC}$ the clay surface has been negatively charged, which will cause an electrostatic repulsion and therefore a decrease in Carbaryl adsorption.

\subsection{Adsorption Isotherm}

The adsorption isotherm was obtained by utilizing the same previous conditions. The concentration range of initial concentration used is 5 to $15 \mathrm{mg} / 1$. The experiences were performed taking into consideration the equilibrium time that is $120 \mathrm{~min}$.

The adsorption capacity of clay for Carbaryl was studied for different initial pesticide concentrations as shown in Figure 12. The results indicated that the adsorption capacity increases with increasing the initial pesticide concentration. The increase in adsorption capacity with concentration is probably due to a high driving force for mass transfer. In fact, high concentration in solution implicates high molecules of pesticide fixed at the surface of the adsorbent. Several theories of adsorption equilibrium were applied for the analysis of equilibrium sorption data obtained.

\subsubsection{Langmuir Model}

The Langmuir adsorption model [22] is established on the following hypotheses: 1) uniformly energetic adsorption sites, 2) monolayer coverage, and 3) no lateral interaction between adsorbed molecules. Graphically, a plateau characterizes the Langmuir isotherm. Therefore, at

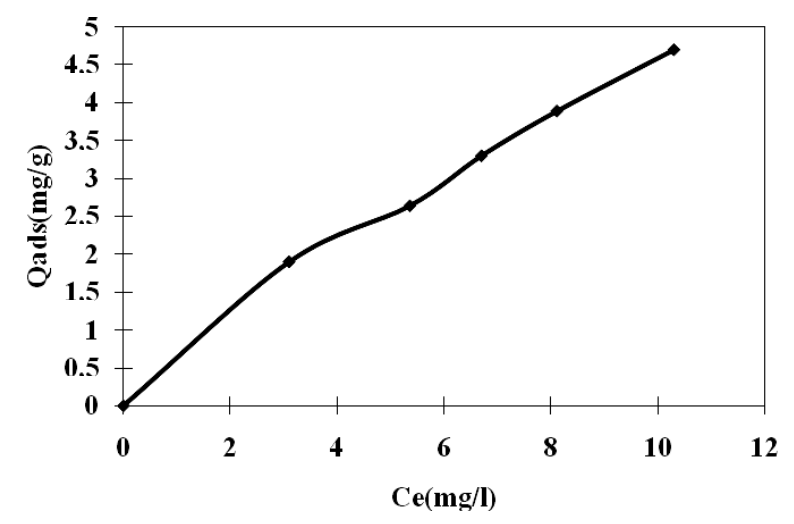

Figure 12. Adsorption isotherm of carbaryl. equilibrium, a saturation point is reached where no further adsorption can occur. A basic assumption is that sorption takes place at specific homogeneous sites within the adsorbent. Once a pesticde molecule occupies a site, no further adsorption can take place at that site. A mathematical expression of the Langmuir isotherm is given by Equation (2):

$$
\mathrm{Q}_{\mathrm{ads}}=\frac{\mathrm{Q}_{\max } \mathrm{K}_{\mathrm{L}} \mathrm{C}_{\mathrm{e}}}{1+\mathrm{K}_{\mathrm{L}} \mathrm{C}_{\mathrm{e}}}
$$

where $\mathrm{Q}_{\mathrm{ads}}(\mathrm{mg} / \mathrm{g})$ is the adsorbed amount at equilibrium, $\mathrm{C}_{\mathrm{e}}$ is the equilibrium pesticide concentration $(\mathrm{mg} / \mathrm{l}), \mathrm{K}_{\mathrm{L}}$ is Langmuir equilibrium constant $(1 / \mathrm{mg})$ and $\mathrm{Q}_{\max }$ the maximum adsorption capacity $(\mathrm{mg} / \mathrm{g})$.

\subsubsection{Freundlich Model}

The Freundlich isotherm endorses the heterogeneity of the surface and assumes that the adsorption occurs at sites with different energy of adsorption. The energy of adsorption varies as a function of surface coverage [23]. This equation is also applicable to multilayer adsorption and is expressed by the following equation:

$$
\mathrm{Q}_{\mathrm{ads}}=\mathrm{K}_{\mathrm{F}} \mathrm{C}_{\mathrm{e}}^{\frac{1}{\mathrm{n}}}
$$

where $\mathrm{K}_{\mathrm{F}}$ is the Freundlich constant and $\mathrm{n}$ is the heterogeneity factor. The $\mathrm{K}_{\mathrm{F}}$ value is related to the adsorption capacity; while $1 / \mathrm{n}$ value is related to the adsorption intensity.

\subsubsection{Analysis of Adsorption Isotherms}

The amounts of adsorbed quantities of Carbaryl at the equilibrium $\left(Q_{\mathrm{ads}}\right)$, versus equilibrium pesticide concentration were drawn in Figure 12. The isotherm form was type L in Giles classification [24]. The experimental adsorption isotherm obtained was compared with the adsorption isotherm models and the constants appearing in each equation of those models were determined by nonlinear regression analysis. The results of these analyses are tabulated in Table 2 . The correlation coefficients $\left(\mathrm{R}^{2}\right)$ are also shown in this table. The table indicates that all the isotherms give reasonable fit to experimental data.

Based on the correlation coefficient, $\mathrm{R}^{2}$ listed in Table 2 , it can be concluded that the adsorption of Carbaryl on our clay at $20^{\circ} \mathrm{C}$ was demonstrated well by both of Langmuir and Freundlich isotherm models. The correlation coefficient, $\mathrm{R}^{2}$ for both models was $0.97 \leq \mathrm{R}^{2} \leq 0.99$. The adsorption process was favorable as Langmuir separation factor, $\mathrm{R}_{\mathrm{L}}$ was $0<\mathrm{R}_{\mathrm{L}}<1$ and supported by $1 / \mathrm{n}$ values of Freundlich which were less than one.

Freundlich's isotherm model, is represented by an equation with two parameters $\left(K_{F}\right.$ and $\left.n\right)$, which consist of exponential distribution of energies of some adsorption sites on the surface of the support, which is characterized by an adsorption in located sites. Furthermore, 
Table 2. Adsorption isotherm constants for adsorption of Carbaryl by clay.

\begin{tabular}{cccccc}
\hline \multicolumn{3}{c}{ Langmuir parameters } & \multicolumn{3}{c}{ Freundlich parameters } \\
\hline $\mathrm{K}_{\mathrm{L}}$ & $\mathrm{Q}_{\max }(\mathrm{mg} / \mathrm{g})$ & $\mathrm{R}^{2}$ & $\mathrm{~K}_{\mathrm{f}}$ & $1 / \mathrm{n}$ & $\mathrm{R}^{2}$ \\
0.067 & 10.75 & 0.970 & 0.776 & 0.763 & 0.990 \\
\hline
\end{tabular}

this is applicable in the case of dilute solutions. The value $1 / \mathrm{n}$ gives an indication on the validity of the adsorption of adsorbent-adsorbate system. A value $1 / \mathrm{n}$ between 0 and 1 that indicates a favorable adsorption [25]. In addition to that, this also indicates that the adsorption capacity increases, and further, adsorption sites appear. When $1 / \mathrm{n}>1$, the adsorption is not favorable, the adsorption connections become weak and the adsorption capacity decreases. The numerical value $1 / \mathrm{n}=0.763$ (Table 2) is related to the adsorption is favorable.

\section{Conclusion}

In this study, the removal of Carbaryl from aqueous solution by this clay, as a natural available adsorbent, was investigated. Adsorption capacity of adsorbent increased with increasing initial concentration of Carbaryl and decreased with increasing temperature. The equilibrium uptake was increased with the increasing of the initial concentration of pesticide in solution. The increase in mass adsorbent leads to increase in pesticide adsorption due to increase in number of adsorption sites. The $\mathrm{pH}$ experiments showed that the significant adsorption takes place in acidic range. A decrease in Carbaryl adsorption is accompanied by increasing the ionic strength of the solution that represented by $\mathrm{NaNO}_{3}$ concentration. The Langmuir and Freundlich adsorption models were used to describe the equilibrium between adsorbed Carbaryl on the adsorbent $\left(\mathrm{Q}_{\mathrm{ads}}\right)$ and Carbaryl in solution $\left(\mathrm{C}_{\mathrm{e}}\right)$ at different temperatures. The equilibrium data were best described by the Freundlich isotherm model. The results show that the natural clay is an excellent adsorbent for the used pesticide. Finally, this local clay can be used as an effective natural adsorbent for the economic treatment of water.

\section{REFERENCES}

[1] J. O. Okonkwo, L. Kampira and D. D. K. Chingakule, "Organochlorine Insecticides Residues in Human Milk: A Study of Lactating Mothers in Siphofaneni," Bulletin of Environmental Contamination and Toxicology, Vol. 63, No. 2, 1999, pp. 243-247. doi:10.1007/s001289900972

[2] A. El Arfaoui Benaomar, "Etude des Processus d'adsorption et de Désorption de Produits Phytosanitaires dans des Sols Calcaires," Ph.D. Thesis, University of Reims Champagne-Ardenne, Reims, 2010.

[3] M. F. D. Oliveira, C. T. Johnston, G. S. Premachandra, B.
J. Teppen, H. Li, D. A. Laird, D. Zhu and S. A. Boyd, "Spectroscopic Study of Carbaryl Sorption on Smectite from Aqueous Suspension," Environmental Science and Technology, Vol. 39, No. 23, 2005, pp. 9123-9129. doi:10.1021/es048108s

[4] R. S. Juang, F. C. Wu and R. L. Tseng, "The Ability of Activated Clay for the Adsorption of Dyes from Aqueous Solutions," Environmental Technology, Vol. 18, No. 5, 1997, pp. 525-531. doi:10.1080/09593331808616568

[5] M. Roulia and A. A. Vass Iliadis, "Interactions between C.I. Basic Blue 41 and Aluminosilicate Sorbents," Journal of Colloid and Interface Science, Vol. 291, No. 1, 2005, pp. 37-44. doi:10.1016/j.jcis.2005.04.085

[6] N. Barka, A. Assabbane, A. Nounah, A. Albourine and Y. Ait-Ichou, "Dégradation Photocatalytique de Deux Colorants Séparés et en Mélange Binaire par $\mathrm{TiO}_{2}$-Supporté," Sciences \&Technologie A, Vol. B, No. 27, 2008, pp. 9-16.

[7] E. Errais, "Réactivité de Surface d'Argiles Naturelles, Etude de l'Adsorption de Colorants Anioniques," Ph.D. Thesis, University of Strasbourg, Strasbourg, 2011.

[8] K. Bellir, "Caractérisation de la Rétention du Cuivre par des Matériaux Naturels Utilisé dans l'Imperméabilisation des Décharges," Ph.D. Thesis, University of Mentouri Constantine, Constantine, 2002.

[9] J. A. Hawkins, "Proceedings of a Symposium Sponsored by the Division of Agrochemicals at the $192^{\text {nd }}$ Meeting of the ACS," Washington, 1987.

[10] J. G. Burg, J. D. Webb, F. W. Knapp and A. H. Cantor, "Field and Laboratory Efficacy Studies of Erythrosin B for Musca Domestica (Diptera: Muscidae) and Drosophila Robusta (Diptera: Drosophilidae) Control," Journal of Economic Entomology, Vol. 82, No. 1, 1989, pp. 171-174.

[11] J. A. Hawkins, M. C. Healey, M. H. Johnson-Delivorias and J. R. Heitz, "The Effect of Erythrosin B on Infective Larvae of Bovine Gastrointestinal Nematodes," Veterinary Parasitol, Vol. 16, No. 1-2, 1984, pp. 35-41. doi:10.1016/0304-4017(84)90006-2

[12] T. S. Anirudhan and M. Ramachandran, "Surfactant-Modified Bentonite as Adsorbent for the Removal of Humic Acid from Wastewaters," Applied Clay Science, Vol. 35, No. 3-4, 2007, pp. 276-281. doi:10.1016/j.clay.2006.09.009

[13] B. Karagozoglu, M. Tasdemir, E. Demirbas and M. Kobya, "The Adsorption of Basic Dye (Astrazon Blue FGRL) from Aqueous Solutions onto Sepiolite, Fly Ash and Apricot Shell Activated Carbon: Kinetic and Equilibrium Studies," Journal of Hazardous Materials, Vol. 147, No. 1-2, 2007, pp. 297-306. doi:10.1016/j.jhazmat.2007.01.003

[14] J. M. Salman and K. A. Al-Saad, "Adsorption of 2,4-Dichlorophenoxyacetic Acid onto Date Seeds Activated Carbon Equilibrium, Kinetic and Thermodynamic Studies," International Journal of Chemical Sciences, Vol. 10, No. 2, 2012, pp. 677-690.

[15] W. T. Tsai, Y. M. Chang, C. W. Lai and C. C. Lo, "Adsorption of Ethyl Violet Dye in Aqueous Solution by Regenerated Spent Bleaching Earth," Journal of Colloid and Interface Science, Vol. 289, No. 2, 2005, pp. 333-338. doi:10.1016/j.jcis.2005.03.087

[16] G. W. Bailey and J. L. White, "Review of Adsorption and 
Desorption of Organic Pesticides by Soil Colloids, with Implication Concerning Pesticide Bioactivity," Journal of Agricultural and Food Chemistry, Vol. 12, No. 4, 1964, pp. 324-332. doi:10.1021/if60134a007

[17] B. Yaron, R. Calvet and R. Prost, "Soil Pollution: Processes and Dynamics," Springer-Verlag, New York, 1996.

[18] N. Barka, K. Ouzaouit, M. Abdennouri and M. El Makhfouk, "Dried Prickly Pear Cactus (Opuntia Ficus Indica) Cladodes as a Low-Cost and Eco-Friendly Biosorbent for Dyes Removal from Aqueous Solutions," Journal of the Taiwan Institute of Chemical Engineers, Vol. 44, No. 1, 2013, pp. 52-60. doi:10.1016/j.jtice.2012.09.007

[19] S. S. Tahir and N. Rauf, "Removal of Cationic Dye from Aqueous Solutions by Adsorption onto Bentonite Clay," Chemosphere, Vol. 63, No. 11, 2006, pp. 1842-1848. doi:10.1016/j.chemosphere.2005.10.033

[20] W. T. Tsai, H. C. Hsu, T. Y. Su, K. Y. Lin, C. M. Lin and T. H. Dai, "The Adsorption of Cationic Dye from Aqueous Solution onto Acid-Activated and Site," Journal of Hazardous Materials, Vol. 147, No. 3, 2007, pp. 10561062. doi:10.1016/j.jhazmat.2007.01.141
[21] C. H. Weng and Y. F. Pan, "Adsorption of a Cationic Dye (Methylene Blue) onto Spent Activated Clay," Journal of Hazardous Materials, Vol. 144, No. 1-2, 2007, pp. 355362. doi:10.1016/i.jhazmat.2006.09.097

[22] I. Langmuir, "The Adsorption of Gases on Plane Surfaces of Glass, Mica, and Platinum," Journal of the American Chemical Society, Vol. 40, No. 9, 1916, pp. 1361-1403. doi:10.1021/ja02242a004

[23] H. M. F. Freundlich, "Over the Adsorption in Solution," Journal of Physical Chemistry, Vol. 57A, 1906, pp. 385470.

[24] C. H. Giles, D. Smith and A. Huitson, "A General Treatment and Classification of the Solute Adsorption Isotherm. I. Theoretical," Journal of Colloid and Interface Science, Vol. 47, No. 3, 1974, pp. 755-765. doi:10.1016/0021-9797(74)90252-5

[25] W. T. Tsai, Y. M. Chang, C. W. Lai and C. C. Lo, “Adsorption of Basic Dyes in Aqueous Solution by Clay Adsorbent from Regenerated Bleaching Earth," Applied Clay Science, Vol. 29, No. 2, 2005, pp. 149-154. doi:10.1016/i.clay.2004.10.004 